\title{
Coronary calcium in patients with and without diabetes: first manifestation of acute or chronic coronary events is characterized by different calcification patterns
}

Joseph Shemesh ${ }^{1,2+}$, Alexander Tenenbaum ${ }^{1,2,3+}$, Enrique Z Fisman ${ }^{2,3^{*}}$, Nira Koren-Morag ${ }^{2}$ and Ehud Grossman ${ }^{1,2}$

\begin{abstract}
Background: Coronary artery calcification (CAC) is closely related to coronary atherosclerosis. However, less is known about the clinical significance of extensive CAC (ECAC) in regard to types of first coronary events (acute vs. chronic). Diabetes mellitus (DM) represents a strong risk factor for CAD although its association with CAC is controversial. Aiming to elucidate these controversies we investigated the long-term outcome of coronary artery disease (CAD) in relation to degree of CAC in patients with and without DM from our annual cheek-up outpatient clinic.
\end{abstract}

Methods: Coronary artery computed tomography (CT) was performed in 667 patients who were yearly evaluated during a mean follow-up period of $6.3 \pm 3.4$ year. The following 4 CAC categories were established: calcium absence; total calcium score (TCS): 1-100 AU; TCS: 101-600 AU and ECAC: TCS above 600 AU. Acute event was defined as first acute myocardial infarction (MI) or a new unstable angina. First chronic event was defined as a positive stress test with a consequent elective percutaneous coronary intervention or coronary artery bypass grafting.

Results: 628 subjects (94\%) were free from any cardiac events, 39 (6\%) experienced first cardiac event: 18 of them suffered acute and 21 chronic events. There were 67 patients with and 600 patients without DM: 78\% of patients with DM presented CAC vs. 50\% of patients without DM $(p<0.001)$.The mean TCS was 17 times higher in the chronic than in the acute events group: 914 vs. $55 \mathrm{AU}, \mathrm{p}<0.001$. In 95\% of the patients with chronic events more than one calcified vessel was found, compared to $67 \%$ of the patients with acute events and only $30 \%$ of those without events $(p<0.001)$. Incidence of CAD events (all types pooled together) rose consequently from $2 \%$ in subjects without CAC to $34 \%$ in subjects with ECAC $(p<0.001)$. However, among the 32 subjects with ECAC, 11 (34\%) developed chronic event while none of them had acute event. In contrast, none of subjects with TCS $=0$ or TCS 1-100 AU presented with chronic events. Subjects with TCS 101-600 AU presented 10 (9\%) chronic and $5(4.5 \%)$ acute events $(p<0.001)$.

Conclusions: Asymptomatic subjects with ECAC are not firstly manifested as acute coronary events but presented a high level of chronic CAD-related events during the $6.3 \pm 3.4$ year follow-up. In contrast, first acute CAD-related events occurred mostly in subjects with mild and moderate CAC score.

Keywords: Angina pectoris, Atherosclerosis, Coronary calcification, Coronary artery disease, Coronary computed tomography, Diabetes mellitus, Myocardial infarction

\footnotetext{
*Correspondence: zfisman@post.tau.ac.il

${ }^{\dagger}$ Equal contributors

${ }^{2}$ Sackler Faculty of Medicine, Tel-Aviv University, 69978 Tel-Aviv, Israel

${ }^{3}$ Cardiovascular Diabetology Research Foundation, 58484 Holon, Israel

Full list of author information is available at the end of the article
} 
Coronary artery calcification (CAC) is a well established surrogate marker of the total burden of coronary atherosclerosis [1-3]. Large prospective studies consistently demonstrated that higher CAC scores are associated with increased risk for coronary artery disease (CAD) related events $[4,5]$ and that addition of CAC score to traditional risk factors improves risk stratification $[5,6]$. Previously, we [7,8] and others [9] have suggested that subjects with extensive CAC (ECAC) are at increased risk of stable angina but not of acute coronary syndrome, compared to the those with the lower CAC scores.Diabetes mellitus (DM) represents a strong risk factor for CAD, albeit its association with CAC is controversial. While a number of studies have found significant relationship between high CAC and DM [10-13], the Multi-Ethnic Study of Atherosclerosis (MESA) did not confirm this association [9]. In an aim to elucidate these controversies we sought to investigate the longterm CAD outcome (stratified according to chronic or acute events) in relation to degree of CAC in patients with and without DM undergoing our annual cheek-up outpatient clinic.

\section{Material and methods \\ Patient selection}

Seven hundred and forty five consecutive subjects who consented to perform a cardiac computed tomography (CT) for coronary calcium evaluation were recruited from our annual cheek-up clinic between January 2001 and January 2002. The inclusion criteria for screening were men above 40 and women above 50 years free of cardiovascular disease. Those who had at least one year of follow-up were included in the present analysis. Seventy six subjects who never returned to the annual check-up were excluded and two others were excluded since an acute MI was found in their files before the study entry. The remaining 667 subjects comprised our study group. All underwent $\mathrm{CT}$ at baseline visit and were then yearly evaluated. The development of events was finally assessed on February 2011. So, the follow-up period was until the first diagnosis of event, death, last annual check -up, or 31 January 2011, providing a maximum follow-up of 10 years, mean $6.3 \pm 3.4$ years.

\section{Events definition}

Only first coronary events were analyzed. We defined acute event as first acute MI or hospitalization for a new unstable angina. Chronic event was defined as positive stress test on the routine annual check-up, with or without chest pain, with a consequent elective coronary catheterization resulting in percutaneous coronary intervention $(\mathrm{PCI})$ or coronary artery bypass grafting (CABG).

\section{Follow-up}

Events were recorded from the files of the annual checkup program in our institute and were verified by the available documentation. Data on mortality and cause of death were available for all participants from the registry of the Ministry of Internal Affairs. A written informed consent was obtained from all patients and the entire study protocol was approved by the Sheba Medical Center Helsinki Committee.

\section{Annual check-up}

All subjects were clinically evaluated at baseline and then annually, and a detailed medical history and standard physical examination were performed. The following variables were recorded: age, height, weight, concomitant diseases, smoking habits, and laboratory evaluation. Estimated glomerular filtration rate (eGFR) was calculated according to the Chronic Kidney Disease Epidemiology Collaboration (CKD-EPI) equation [14].

\section{Coronary CT}

All CT scans were performed on a dual-detector spiral CT without ECG gating and without contrast injection. Scanning protocol and CAC measuring were done according to a previously published protocol using the modified Agatston method [15]. Total CAC score was the sum of all the individual calcific lesions identified within the area of the coronary arteries. The reproducibility of calcification scoring by this method is high, with an intra class correlation coefficient of 0.99 and of 0.94 for inter-observer agreement [16]. The following 4 CAC categories were distinguished: absence of CAC; mildmoderate CAC: 1-100 AU; high CAC: 101-600 AU and very high ECAC score: above $600 \mathrm{AU}$, which corresponds to the $95^{\text {th }}$ percentile in our cohort.

A TCS $>0$ was considered positive for the presence of any CAC. The number of coronary vessels with CAC was recorded for each subject and defined as having at least one calcific lesion in one of the 4 regions: main left artery, left anterior descending artery (LAD) and its branches, left circumflex artery (LCX) and its branches and right coronary artery (RCA) and its branches.

\section{Assessment of cardiovascular risk factors}

Height and weight were measured with participants wearing light clothing without shoes. The body mass index (BMI) was calculated as weight $(\mathrm{Kg})$ divided by the square of the height. Blood pressure (BP) was measured in the seated position after 3 minutes of rest. Hypertension was defined when BP levels were twice $\geq 140 \mathrm{~mm} \mathrm{Hg}$ for systolic BP and/or $\geq 90 \mathrm{~mm} \mathrm{Hg}$ for diastolic BP or a history of hypertension was reported or when the subject was on antihypertensive medications. Diabetes mellitus (DM) was defined when fasting plasma 
Table 1 Baseline characteristics of the study population

\begin{tabular}{|c|c|c|c|c|}
\hline Characteristics & No event $N=628$ & Acute event $\mathrm{N}=18$ & Chronic event $\mathrm{N}=21$ & $p$ value \\
\hline Age & $55 \pm 7.2$ & $57 \pm 8.2$ & $60 \pm 7.7$ & 0.007 \\
\hline Male gender & $526(84)$ & $17(94)$ & $21(100)$ & 0.073 \\
\hline BMI (kg/m2) & $27.0 \pm 3.5$ & $27.7 \pm 4.0$ & $26.2 \pm 2.7$ & 0.395 \\
\hline $\mathrm{SBP}(\mathrm{mmHg})$ & $126 \pm 17$ & $124 \pm 15$ & $130 \pm 13$ & 0.444 \\
\hline $\mathrm{DBP}(\mathrm{mmHg})$ & $79 \pm 9$ & $78 \pm 9$ & $79 \pm 6$ & 0.906 \\
\hline Hypertension & $163(26)$ & $5(28)$ & $12(57)$ & 0.007 \\
\hline Diabetes & $60(10)$ & $3(17)$ & $4(19)$ & 0.232 \\
\hline Current smokers & $106(22)$ & $4(33)$ & $5(31)$ & 0.454 \\
\hline Chronic renal failure & $14(2)$ & $1(6)$ & $1(5)$ & 0.511 \\
\hline CAD family history & $162(26)$ & $3(18)$ & $7(35)$ & 0.486 \\
\hline Hyperlipidemia & $284(47)$ & $9(50)$ & $12(60)$ & 0.475 \\
\hline Urea (mg/dl) & $33 \pm 7.7$ & $35 \pm 7.7$ & $32 \pm 5.7$ & 0.557 \\
\hline Creatinine (mg/dl) & $1.07 \pm 0.15$ & $1.08 \pm 0.17$ & $1.13 \pm 0.11$ & 0.179 \\
\hline Glucose (mg/dl) & $99 \pm 23$ & $96 \pm 18$ & $101 \pm 21$ & 0.761 \\
\hline Calcium (mg/dl) & $9.6 \pm 0.45$ & $9.6 \pm 0.46$ & $9.6 \pm 0.50$ & 0.908 \\
\hline Phosphorus (mg/dl) & $3.02 \pm 0.50$ & $2.76 \pm 0.27$ & $3.0 \pm 0.69$ & 0.088 \\
\hline Triglyceride (mg/dl) & $143 \pm 79$ & $156 \pm 63$ & $133 \pm 58$ & 0.671 \\
\hline \multicolumn{5}{|l|}{ Total cholesterol (mg/dl) } \\
\hline HDL-cholesterol (mg/dl) & $45 \pm 12$ & $40 \pm 5$ & $451 \pm 3$ & 0.243 \\
\hline LDL-cholesterol (mg/dl) & $127 \pm 29$ & $127 \pm 37$ & $127 \pm 26$ & 0.999 \\
\hline
\end{tabular}

Data are number (\%) of patients or mean \pm SD.

glucose was on 2 occasions greater than $126 \mathrm{mg} / \mathrm{dL}$ (7.0 $\mathrm{mmol} / \mathrm{L})$, a history of DM was reported or when the patient was on insulin or oral hypoglycemic medications. Hypercholesterolemia was defined when measured total cholesterol was $>250 \mathrm{mg} / \mathrm{dl}$, or when the patient reported medication with cholesterol lowering agents. Smoking status was determined according to the questionnaire.

\section{Statistical methods}

Data were analyzed with IBM SPSS software version 21.0 and were presented as frequencies and percentages for categorical variables and as mean and standard deviation for continuous variables. Significance levels were set at 0.05. The distributions of continuous variables in the study were examined using the Kolmogorov-Smirnov non-parametric test. To demonstrate the differences between the event groups (no event, chronic event and acute event), Chi-Square tests were analyzed for differences in categorical baseline characteristics and incidence of events between the groups. One-way ANOVA tests were performed for continuous characteristic including TCS values, following by analysis of covariance (ANCOVA) to adjust for age as a potential covariate.

\section{Results}

The mean period of follow-up was $6.3 \pm 3.4$ year. During this period 628 subjects (94\%) were free from any cardiac events (Group I). Throughout follow up 39 (6\%) of patients experienced a cardiac event: 18 of them suffered acute events (13 acute MI and 5 unstable angina pectoris -

Table 2 The CAC characteristics according to outcome during follow-up

\begin{tabular}{lllll}
\hline Variable & No event $\mathbf{N}=\mathbf{6 2 8}$ & Acute event $\mathbf{N}=\mathbf{1 8}$ & Chronic event $\mathbf{N}=\mathbf{2 1}$ & $\mathbf{p}$ value \\
\hline TCS mean (SD) & $93 \pm 276$ & $55 \pm 62$ & $914 \pm 660$ & $<0.001$ \\
$\mathrm{TCS}>0$ & $311(50)$ & $13(72)$ & $21(100)$ & $<0.001$ \\
$\mathrm{CV}>1$ & $187(30)$ & $12(67)$ & $20(95)$ & $<0.001$ \\
No CV mean (SD) & $1.02 \pm 1.15$ & $1.72 \pm 1.23$ & $3.05 \pm 0.74$ & $<0.001$ \\
\hline
\end{tabular}

TCS - Total calcium score (AU); CV - calcified vessel >1 - more than one calcified major coronary vessel in one of the 4 regions: main left artery, LAD, LCX and RCA including their branches; No CV - mean number of calcified major coronary vessels.

For TCS $>0$ and $C V>1$ data are number (\%) of patients. 
Table 3 Incidence of acute and chronic events by TCS categories

\begin{tabular}{llllll}
\hline $\begin{array}{l}\text { Type of } \\
\text { event }\end{array}$ & TCS $=\mathbf{0}$ & TCS $\mathbf{1 - 1 0 0}$ & TCS 101-600 & TCS $>$ 600 & $\begin{array}{l}\mathbf{p} \text { value } \\
\text { (age-adjusted) }\end{array}$ \\
\hline All types & $\mathbf{N = 3 1 5}$ & $\mathbf{N}=\mathbf{2 0 8}$ & $\mathbf{N}=\mathbf{1 1 2}$ & $\mathbf{N}=\mathbf{3 2}$ & $11(34)$ \\
Acute & $5(2)$ & $8(4)$ & $15(13.5)$ & 0 & $<0.001$ \\
Chronic & $5(2)$ & $8(4)$ & $5(4.5)$ & $11(34)$ & \\
\hline
\end{tabular}

Data are number (\%) of patients.

TCS - Total calcium score (AU).

Group II) and in 21 of them chronic events were documented (Group III). Eight patients died without having any known prior cardiac event (non-cardiac death).

The baseline characteristics of the participants are given in Table 1. Patients with events were older than those without and those with chronic events were older than those with acute. The frequency of hypertension was twice higher among those with chronic than in those with acute event and no events. All the other clinical and laboratory parameters were not statistically different between study groups. There were 67 patients with and 600 patients without diabetes in our study. It should be pointed out that $78 \%$ of the patients with DM had CAC (TCS above zero) vs. $50 \%$ of patients without DM $(\mathrm{p}<0.001)$.

The CAC characteristics of patients are given in Table 2 . Among subjects without events half had CAC $($ TCS $>0$ ) while all those with chronic and three quarter of the acute events group had CAC. Equally, the mean CAC score was 10 times higher in the chronic events group than in those without events (914 vs. $93 \mathrm{AU}$ ) and 17 times higher than the mean TCS of the acute group ( 914 vs. 55 AU). Ninety five percent of the patients with chronic events had more than one calcified vessel compared to $67 \%$ of the patients with acute events and only $30 \%$ of those without events $(\mathrm{p}<0.001)$.

The incidence of acute and chronic events by TCS categories is given in Table 3 and Figure 1. During followup incidence of the CAD events (all types pooled together) rose consequently from $2 \%$ in subjects without CAC to $34 \%$ in subjects with the highest CAC category TCS $>600$ AU $(\mathrm{p}<0.001)$. However, different pattern in the development of the first acute and chronic coronary events in accordance with the CAC category was observed. Among the 32 subjects with TCS $>600$ AU, 11 (34\%) developed chronic event while none of them had acute event. In contrast, none of subjects with TCS $=0$ or TCS 1-100 AU had chronic events. Subjects with TCS 101-600 AU presented 10 (9\%) chronic and 5 $(4.5 \%)$ acute events $(\mathrm{p}<0.001)$.

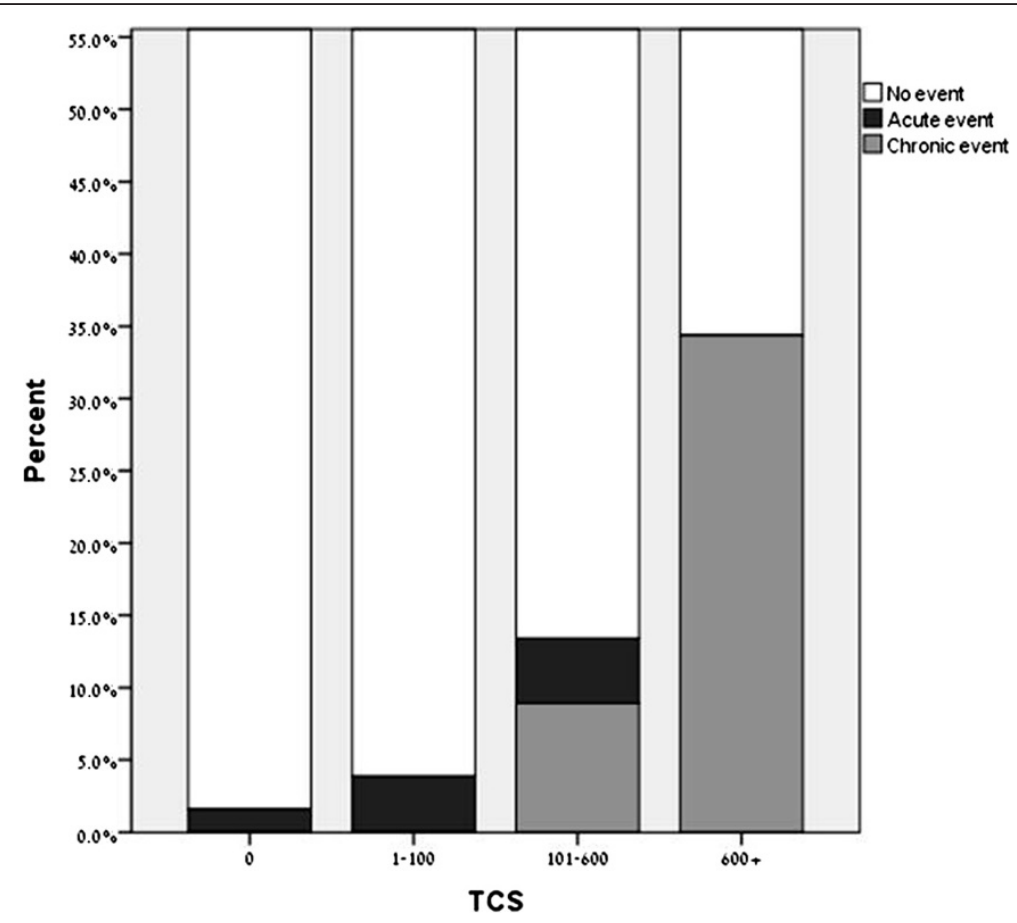

Figure 1 Incidence of acute and chronic events by TCS categories. TCS - Total calcium score (AU). 


\section{Discussion}

The main finding of our study is that asymptomatic subjects with ECAC, both with and without DM did not developed first acute CAD-related events during up to 10 years of follow-up. Our data support the suggestion that ECAC is associated with a stable form of atherosclerosis which is mainly manifested by a chronic rather than acute course of CAD [7-9].

Previous studies have shown a dramatically increased incidence rate of CAD events (when all types of events pooled together) among those with the highest levels of CAC compared to those with CAC $=$ zero [3-6]. However, as we demonstrate in the current analysis, a different pattern in development of acute and chronic coronary events in accordance with CAC category can be distinguished. The acute events in our study occurred mostly in subjects with mild and moderate CAC and even in absence of CAC. This might have an important clinical relevance, since minimal or mild CAC should not be categorized into a lower risk category (as suggested by the SHAPE investigators) [17]. These findings are also supported by histopathological studies, intravascular ultrasound and CT observations that consistently demonstrated that acute events rise mainly from soft non-calcified or mildly calcified plaques [18-27]. In a series of cases of sudden coronary death, more than $50 \%$ of thin-cap fibroatheromas showed a lack of calcification or only speckled calcification on postmortem radiographs of coronary arteries [18]. Several studies demonstrated the destabilizing effect of the lipid core, whereas presence of calcium was a stabilizing force and calcified lesions were more resistant to rupture (similar to fibrous plaque) $[19,20]$.

Thus, it seems that ECAC represents a long standing chronic stage of slowly growing coronary atherosclerosis and can be regarded as a healing process leading to stabilization and decrease vulnerability of the plaques [28]. On the other hand, ECAC causes negative vessels remodeling resulting in flow restriction and leading to clinical manifestations such as chronic angina or silent ischemia upon a routine stress test [18-28].

The prevalence of CAC in our patients with DM was significantly higher than in patients without DM. The clinical value of CAC score in diabetic patients has been recently demonstrated in several studies: CAC score can further stratify diabetic patients according to the presence and extent of CAC into patients with very low or high CV risk [10-13,29].

It should be stated that our population was predominantly masculine, and this may represent a potential limitation since the epicardial adipose tissue volume shows gender disparities, being strongly associated with coronary atherosclerosis in men [30]. Therefore, despite of the strong theoretical background and biological plausibility, caution should be used in interpreting our findings because it was not a randomized controlled trial and we cannot rule out other factors that could have influenced the observed clinical outcomes.

\section{Conclusions}

Asymptomatic subjects with ECAC did not develop first acute events, but presented a high level of chronic CADrelated events during a long term follow-up. In contrast, most of the acute CAD-related events firstly occurred in subjects with mild and moderate CAC.

\section{Abbreviations \\ AU: Agatston units; BP: Blood pressure; BMI: Body mass index; CABG: Coronary artery bypass grafting; CAD: Coronary artery disease; CAC: Coronary artery calcification; CT: Computed tomography; DM: Diabetes mellitus; ECAC: Extensive coronary artery calcification; LAD: Left anterior descending artery; LCX: Left circumflex artery; MI: Myocardial infarction; PCl: Percutaneous coronary intervention; RCA: Right coronary artery; TCS: Total calcium score.}

\section{Competing interests}

All authors declare that they have no competing interests.

\section{Authors' contributions}

JS and EG conceived the study, JS, AT and EZF drafted the manuscript, JS, AT, EG and NKM were involved in the study design, coordination and data acquisition, JS and NKM studied and matched the records from the computed Registry, EZF, AT, JS and EG interpreted the results, NKM performed the statistical analysis of the data presented, AT, EZF and EG critically reviewed the study for important intellectual content. All authors approved the final version of the manuscript.

\section{Acknowledgements}

This work was supported in part by the Cardiovascular Diabetology Research Foundation (RA 58-040-684-1), Holon, Israel.

\section{Author details}

${ }^{1}$ Cardiac Rehabilitation Institute, Sheba Medical Center, 52621 Tel-Hashomer, Israel. ${ }^{2}$ Sackler Faculty of Medicine, Tel-Aviv University, 69978 Tel-Aviv, Israel.

${ }^{3}$ Cardiovascular Diabetology Research Foundation, 58484 Holon, Israel.

Received: 12 September 2013 Accepted: 1 November 2013

Published: 5 November 2013

\section{References}

1. Rumberger JA, Simons DB, Fitzpatrick LA, Sheedy PF, Schwartz RS: Coronary artery calcium area by electron-beam computed tomography and coronary atherosclerotic plaque area. A histopathologic correlative study. Circulation 1995, 92:2157-2162.

2. Sangiorgi G, Rumberger JA, Severson A, Edwards WD, Gregoire J, Fitzpatrick LA Schwartz RS: Arterial calcification and not lumen stenosis is highly correlated with atherosclerotic plaque burden in humans: a histologic study of 723 coronary artery segments using nondecalcifying methodology. J Am Coll Cardiol 1998, 31:126-133.

3. Greenland P, Alpert JS, Beller GA, Benjamin EJ, Budoff MJ, Fayad ZA, Foster E, Hlatky MA, Hodgson JM, Kushner FG, Lauer MS, Shaw LJ, Smith SC Jr, Taylor AJ, Weintraub WS, Wenger NK, Jacobs AK: 2010 ACCF/AHA guideline for assessment of cardiovascular risk in asymptomatic adults: a report of the American college of cardiology foundation/American heart association task force on practice guidelines. American college of cardiology foundation/ American heart association task force on practice guidelines. Circulation 2010, 122:e584-e636.

4. Detrano R, Guerci AD, Carr JJ, Bild DE, Burke G, Folsom AR, Liu K, Shea S, Szklo M, Bluemke DA, O'Leary DH, Tracy R, Watson K, Wong ND, Kronmal RA: Coronary calcium as a predictor of coronary events in four racial or ethnic groups. New Engl J Med 2008, 358:1336-1345.

5. Erbel R, Möhlenkamp S, Moebus S, Schmermund A, Lehmann N, Stang A Dragano N, Grönemeyer D, Seibel R, Kälsch H, Bröcker-Preuss M, Mann K, 
Siegrist J, Jöckel KH, Heinz Nixdorf Recall Study Investigative Group: Coronary risk stratification, discrimination, and reclassification improvement based on quantification of subclinical coronary atherosclerosis: the Heinz Nixdorf Recall study. J Am Coll Cardiol 2010, 56:1397-1406

6. Polonsky TS, McClelland RL, Jorgensen NW, Bild DE, Burke GL, Guerci AD, Polonsky TS, McClelland RL, Jorgensen NW, Bild DE, Burke GL, Guerci AD, Greenland P: Coronary artery calcium score and risk classification for coronary heart disease prediction. JAMA 2010, 303:1610-1616.

7. Shemesh J, Stroh Cl, Tenenbaum A, Hod H, Boyko V, Fisman EZ, Motro M: Comparison of coronary calcium in stable angina pectoris and in first acute myocardial infarction utilizing double helical computerized tomography. Am J Cardiol 1998, 81:271-275.

8. Shemesh J, Apter S, Itzchak Y, Motro M: Coronary calcification compared in patients with acute versus in those with chronic coronary events by using dual-sector spiral CT. Radiology 2003, 226:483-488.

9. Coylewright M, Rice K, Budoff MJ, Blumenthal RS, Greenland P, Kronmal R, Barr RG, Burke GL, Tracy R, Post WS: Differentiation of severe coronary artery calcification in the multi-ethnic study of atherosclerosis. Atherosclerosis 2011, 219:616-622.

10. Elkeles RS, Godsland IF, Feher MD, Rubens MB, Roughton M, Nugara F, Humphries SE, Richmond W, Flather MD, PREDICT Study Group: Coronary calcium measurement improves prediction of cardiovascular events in asymptomatic patients with type 2 diabetes: the PREDICT study. Eur Heart J 2008, 29:2244-2251.

11. Bulugahapitiya $U$, Siyambalapitiya $S$, Sithole J, Idris L: Is diabetes a coronary risk equivalent? Systematic review and meta-analysis. Diabet Med 2009, 26:142-148.

12. Qu W, Le TT, Azen SP, Xiang M, Wong ND, Doherty TM, Detrano RC: Value of coronary artery calcium scanning by computed tomography for predicting coronary heart disease in diabetic subjects. Diabetes Care 2003, 26:905-910.

13. Raggi $P$, Shaw $L J$, Berman DS, Callister TQ: Prognostic value of coronary artery calcium screening in subjects with and without diabetes. J Am Coll Cardiol 2004, 43:1663-1669.

14. Levey AS, Stevens LA, Schmid CH, Zhang YL, Castro AF 3rd, Feldman HI, Kusek JW, Eggers P, Van Lente F, Greene T, Coresh J, CKD-EPI (Chronic Kidney Disease Epidemiology Collaboration): A new equation to estimate glomerular filtration rate. Ann Intern Med 2009, 150:604-612.

15. Shemesh J, Apter S, Rozenman J, Lusky A, Rath S, Itzchak Y, Motro M: Calcification of coronary arteries: detection and quantification with double-helix CT. Radiology 1995, 197:779-783.

16. Broderick LS, Shemesh J, Wilensky RL, Eckert GJ, Zhou X, Torres WE, Balk MA, Rogers WJ, Conces DJ Jr, Kopecky KK: Measurement of coronary artery calcium with dual-slice helical CT compared with coronary angiography: evaluation of $C T$ scoring methods, interobserver variations, and reproducibility. Am J Roentgenol 1996, 167:439-444.

17. Naghavi M, Falk E, Hecht HS, Jamieson MJ, Kaul S, Berman D, Fayad Z, Budoff MJ, Rumberger J, Naqvi TZ, Shaw LJ, Faergeman O, Cohn J, Bahr R, Koenig W, Demirovic J, Arking D, Herrera VL, Badimon J, Goldstein JA, Rudy Y, Airaksinen J, Schwartz RS, Riley WA, Mendes RA, Douglas P, Shah PK, SHAPE Task Force: From vulnerable plaque to vulnerable patient-part III: executive summary of the screening for heart attack prevention and education (SHAPE) task force report. Am J Cardiol 2006, 98:2H-15H.

18. Burke AP, Weber DK, Kolodgie FD, Farb A, Taylor AJ, Virmani R: Pathophysiology of calcium deposition in coronary arteries. Herz 2001 26:239-244.

19. Huang H, Virmani R, Younis H, Burke AP, Kamm RD, Lee RT: The impact of calcification on the biomechanical stability of atherosclerotic plaques. Circulation 2001, 103:1051-1106.

20. Cheng GC, Loree HM, Kamm RD, Fishbein MC, Lee RT: Distribution of circumferential stress in ruptured and stable atherosclerotic lesions. A structural analysis with histopathological correlation. Circulation 1993, 87:1179-1187.

21. Schoenhagen P, Ziada KM, Kapadia SR, Crowe TD, Nissen SE, Tuzcu EM: Extent and direction of arterial remodeling in stable versus unstable coronary syndromes: an intravascular ultrasound study. Circulation 2000, 101:598-603.

22. Rasheed Q, Nair R, Sheehan H, Hodgson JM: Correlation of intracoronary ultrasound plaque characteristics in atherosclerotic coronary artery disease patients with clinical variables. Am J Cardiol 1994, 73:753-758.
23. Rasheed Q, Nair RN, Sheehan HM, Hodgson JM: Coronary artery plaque morphology in stable angina and subsets of unstable angina: an in vivo intracoronary ultrasound study. Int J Card Imagin 1995, 11:89-95.

24. Mintz GS, Pichard AD, Popma JJ, Kent KM, Satler LF, Bucher TA, Leon MB: Determinants and correlates of target lesion calcium in coronary artery disease: a clinical, angiographic and intravascular ultrasound study. J Am Coll Cardiol 1997, 29:268-274.

25. Ehara S, Kobayashi Y, Yoshiyama M, Shimada K, Shimada Y, Fukuda D, Nakamura Y, Yamashita H, Yamagishi H, Takeuchi K, Naruko T, Haze K, Becker AE, Yoshikawa J, Ueda M: Spotty calcification typifies the culprit plaque in patients with acute myocardial infarction: an intravascular ultrasound study. Circulation 2004, 110:3424-3429.

26. Motoyama S, Kondo T, Sarai M, Sugiura A, Harigaya H, Sato T, Inoue K, Okumura M, Ishii J, Anno H, Virmani R, Ozaki Y, Hishida H, Narula J: Multislice computed tomographic characteristics of coronary lesions in acute coronary syndromes. J Am Coll Cardiol 2007, 50:319-326.

27. Pundziute G, Schuijf JD, Jukema JW, Decramer I, Sarno G, Vanhoenacker PK, Boersma E, Reiber JH, Schalij MJ, Wijns W, Bax JJ: Evaluation of plaque characteristics in acute coronary syndromes: non-invasive assessment with multi-slice computed tomography and invasive evaluation with intravascular ultrasound radiofrequency data analysis. Eur Heart J 2008, 29:2373-2381.

28. Yalta K, Yalta T, Yucel O, Sivri N: Extensive coronary arterial calcification: an over-adaptive phenomenon against complications of atherosclerosis? Int J Cardiol 2011, 146:227-228.

29. Lau KK, Wong YK, Chan YH, Yiu KH, Teo KC, Li LS, Ho SL, Chan KH, Siu CW, Tse HF: Prognostic implications of surrogate markers of atherosclerosis in low to intermediate risk patients with type 2 diabetes. Cardiovasc Diabetol 2012, 11:101.

30. Dagvasumberel M, Shimabukuro M, Nishiuchi T, Ueno J, Takao S, Fukuda D, Hirata Y, Kurobe H, Soeki T, Iwase T, Kusunose K, Niki T, Yamaguchi K, Taketani Y, Yagi S, Tomita N, Yamada H, Wakatsuki T, Harada M, Kitagawa T, Sata M: Gender disparities in the association between epicardial adipose tissue volume and coronary atherosclerosis: a 3-dimensional cardiac computed tomography imaging study in Japanese subjects. Cardiovasc Diabetol 2012, 11:106.

\section{doi:10.1186/1475-2840-12-161}

Cite this article as: Shemesh et al: Coronary calcium in patients with and without diabetes: first manifestation of acute or chronic coronary events is characterized by different calcification patterns. Cardiovascular Diabetology 2013 12:161.

\section{Submit your next manuscript to BioMed Central and take full advantage of:}

- Convenient online submission

- Thorough peer review

- No space constraints or color figure charges

- Immediate publication on acceptance

- Inclusion in PubMed, CAS, Scopus and Google Scholar

- Research which is freely available for redistribution

Submit your manuscript at www.biomedcentral.com/submit
C) Biomed Central 